\title{
Trazando la corriente dominante: Contribuciones de la televisión a las orientaciones políticas
}

\author{
GEORGE GEBNER, LARRY GROSS, MICHAEL \\ MORGAN, NANCY SIGNORIELLI *
}

Recientes hallazgos ayudan a matizar el paradigma de Indicadores $\mathrm{Cul}$ turales y sugieren nuevas vias de pensar sobre la televisión, asi como sobre la formación de perspectivas politicas.

La televisión es parte esencial de nuestra vida diaria, revistiéndola de particulares significados. Este es un informe de una investigación sobre la relevancia política de esos significados. Constituye una parte de nuestro proyecto en marcha llamado Indicadores Culturales ${ }^{1}$ y desarrolla nuestro paradigma de «sobreinclusión», publicado por primera vez en esta revista (6).

Primeramente haremos una introducción del contexto teórico y de investigación en el cual presentamos nuestros hallazgos. Posteriormente resumiremos nuestra teoría de la televisión y aplicaremos nuestro paradigma a las orientaciones políticas. Utilizaremos los datos de este estudio para mostrar la contribución de la televisión a las orientaciones políticas, en problemas tales como minorías y derechos civiles, libertad de expresión, gastos gubernamentales e impuestos. Las implicaciones de nuestros hallazgos cuestionan las teorías convencionales sobre el papel de la prensa en el proceso político, y sugieren nuevas vías de pensamiento sobre la televisión, así como sobre la investigación política.

Algunas concepciones sobre el papel de la prensa han constituido una característica central de la moderna teoría política. Una prensa secular de política y comercio fue instrumental en el nacimiento de una diversa masa pública independiente de la iglesia y la nobleza. La prensa era (y es) un órgano relativamente específico y selectivo usado por los más cultos de cada clase. La libertad de prensa, al defender los intereses de partidos y grupos (incluyendo clases) y al cultivar perspectivas opuestas y de conflicto, se suponía que sostenía la pluralidad política presumiblemente necesaria para un gobierno representativo en una sociedad compleja.

El declive de la prensa de partido y, consiguientemente, de los mismos partidos políticos como principales medios de comunicación con los votantes, limita la viabilidad de la teoría de la prensa como defensora del pluralismo ideológico. El predominio que va adquiriendo un sistema de prensa único, orientado hacia el mercado, patrocinado por los anunciantes y, por tanto, ideológicamente más coherente, que reclama una mayor objeti-

* Journal of Communication, 1982, 32, 2, págs. 100-127. Traducción: Mercedes López. 
vidad periodística, e invoca la protección constitucional de sus libertades, para anticipar virtualmente el mercado de ideas de masas, incluso subraya el concepto tradicional del papel de la prensa en la teoría democrática de la política.

Sin embargo, la cultura basada en la imprenta y orientada literariamente, de la cual parten nuestras asunciones políticas, aún ofrece la posibilidad de alguna relativa diversidad de perspectivas y selectividad de usos. Comparada con las tensiones históricas calificativas de la aplicabilidad de las teorías fundamentadas en la era de la imprenta, el reto de la televisión, y del sistema de telecomunicaciones del que la televisión es su centro cultural, es cualitativamente diferente ${ }^{2}$.

La televisión es un sistema centralizado de narrar la historia. Sus dramas, anuncios, noticias, y otros programas llevan un mundo relativamente coherente de imágenes y mensajes comunes a cada hogar televidente. La gente ha nacido ahora dentro del ambiente simbólico de la televisión y vive con sus repetitivas lecciones a lo largo de la vida. La televisión cultiva desde el principio las predisposiciones genuinas que influyen en los usos y selecciones culturales futuros. Trascendiendo barreras históricas de cultura y movilidad, la televisión se ha convertido en la principal y más común fuente de cultura cotidiana de una población diversa y heterogénea.

Muchos de los que actualmente dependen de la televisión, nunca, anteriormente, habían tomado parte en una cultura política nacionalmente compartida. La televisión suministra, quizá por primera vez desde la religión preindustrial, un fuerte vínculo cultural entre las élites y el resto del públi$\mathrm{co}$, un ritual diario compartido y con contenido altamente informativo e irresistible. ¿Cuál es el papel de esta experiencia común en la socialización general y en la orientación política de los americanos? Esa cuestión, de importancia política y de gran impacto social, no ha sido aún debidamente analizada ${ }^{3}$.

Las razones para este retraso son financieras, metodológicas y conceptuales. Las exigencias de la investigación en ciencias sociales, impiden mantener un desarrollo teórico basado en largos períodos de tiempo. Las metodologías de investigación que tienen que ver con la exposición selectiva y los efectos de la comunicación orientada específicamente, se han mostrado inadecuados para el estudio de sistemas simbólicos ampliamente difundidos, para extensos guiones en el ámbito simbólico y para desplazamientos culturales lentos pero masivos. La concentración de la investigación en las actitudes individuales y en el cambio de comportamiento, ha inhibido la investigación de transformaciones conjuntas en el estilo de vida de generaciones (como aquellas nacidas antes y después de la televisión, o dentro de hogares consumidores duros o ligeros de televisión) que permanecen estables para los individuos. Finalmente, el que la investigación sobre comunicación política se haya focalizado sobre comunicaciones (o noticias) explícitamente "políticas" ha oscurecido la compleja naturaleza de la socialización política, especialmente en la era de la televisión en la que el complejo espectro de tipos de programas (la mayor parte de ellos dramas) juega una parte importante.

Nuestra oportunidad para afrontar el problema más amplio llega después de más de una década de recogida de datos y de análisis describiendo 
el mundo de la televisión e identificando las concepciones de la realidad de los televidentes.

El proyecto de Indicadores Culturales emplea una doble estrategia de investigación. A la primera la llamamos análisis de sistemas de mensaje y a la segunda análisis de cultivo. Ambas tienen que ver con $-\mathrm{y}$ ayudan a desarrollar - una concepción de las posiciones históricas e institucionales de la televisión, sus roles y función.

Para el análisis de sistemas de mensaje registramos y analizamos ejemplos de los dramas de la televisión a lo largo de la semana y obtuvimos datos de cada año desde 1967. Sometimos esas muestras semanales a un riguroso y detallado análisis de contenido para determinar las características seleccionadas del mundo de la televisión. Estas características las consideramos como potenciales lecciones de televisión y las usamos como fuentes de preguntas para la segunda estrategia de la investigación. En èl «análisis de cultivo» examinamos las respuestas de televidentes duros y ligeros a esas preguntas, expresadas en frases referidas al mundo real (los no televidentes eran muy pocos y demográficamente muy esparcidos para realizar una investigación seria).

Queríamos determinar si aquellos que invierten la mayoría de su tiempo con la televisión son más proclives a responder a estas preguntas, de modo que reflejen las lecciones potenciales del mundo televisivo (la respuesta televisiva), que aquellos grupos que ven menos televisión, pero que en otros aspectos (sus características demográficas importantes) son comparables a los televidentes duros.

Hemos usado el concepto de «cultivo» para describir la contribución de la televisión a las concepciones de los televidentes. "Cultivo diferencial» es el término empleado por nosotros para las diferencias en los porcentajes de «respuestas televisivas" dadas, dentro de grupos comparables de televidentes duros y ligeros ${ }^{4}$.

Analizando sucesivamente una cuestión tras otra, nos hemos encontrado con que los supuestos, las creencias y los valores de los televidentes duros difieren sistemáticamente de los de los televidentes ligeros en los mismos grupos demográficos. Las diferencias tienden a reflejar al mismo tiempo qué cosas existen y cómo funcionan las cosas en el mundo de la televisión. Algunas veces esas diferencias se mantienen en toda la gama de respuestas, lo que significa que aquellos que ven más televisión tienen una probabilidad mayor -en todos o en la mayor parte de los subgrupos-- de dar «respuestas de televisión» a nuestras preguntas. Pero en muchos casos las pautas son más complejas. Hemos encontrado que ver la televisión puede relacionarse de formas diferentes pero consistentes con visiones del mundo y situaciones vitales de distintos grupos. Hemos denominado a la más general de esas pautas consistentes «sobreinclusión».

$\mathrm{La}$ «corriente dominante" se puede conceptuar como una comunalidad relativa de puntos de vista y de valores que la exposición a las características y a la dinámica del mundo de la televisión tiende a cultivar. Por «sobreinclusión» queremos dar a entener la expresión de esa comunalidad por parte de los televidentes duros en aquellos grupos demográficos cuyos televidentes ligeros mantienen puntos de vista divergentes. En otras palabras, las diferencias encontradas en las respuestas de los diferentes grupos de televidentes, diferencias que pueden ser asociadas a otras características cultu- 
rales, sociales o políticas de estos grupos, pueden estar disminuidas o incluso ausentes de las respuestas de televidentes duros en los mismos grupos 5 .

Nuestro concepto de cultivo relaciona el proceso con las características y con la dinámica del contenido televisivo que son las partes más estables y repetitivas del ritual, y que están presentes en diferentes tipos de programas. La razón es que los televidentes duros ven más cantidad de todo tipo de programas. La disponibilidad del televidente determina las evaluaciones de los programas y las pautas de exposición (fig. 2). Más aún, nuestro análisis del sistema de mensajes encuentra que características generales, tales como demografía, estructura de acción y destino de los personajes son similares en la mayoría de los tipos de programas. Por tanto, son estas características generales y la dinámica del mundo representado en el tiempo de máxima audiencia, y no los programas específicos, las que con mayor probabilidad cultivarían las perspectivas y orientaciones más omnipresentes de los televidentes duros. Así pues, para comprender, e incluso para descubrir, la sustancia de las cuestiones implicadas en el proceso del cultivo, tenemos que saber algo sobre la naturaleza de la corrientes dominante y el contexto institucional de su creación.

El vivir con la televisión significa crecer en un entorno simbólico conformado para servir a las instituciones.

La creación de ese entorno es un proceso rígidamente controlado. La televisión comercial no está, de hecho, abierta al acceso público; retirada de la participación pública por medio del mercado de consumidores, el buzón de reclamaciones o las urnas electorales; protegida del gobierno público por lás interpretaciones actuales de la Primera Enmienda de la Constitución; y sin embargo otorgada mediante licencias públicas y de tal forma protegida que convierten al medio en dependiente del gobierno de las corporaciones privadas ${ }^{6}$. El mecanismo económico que guía este gobierno es la publicidad, un gasto empresarial deducible de los impuestos, soportado por todos los consumidores independientemente de su uso del medio. Los patrocinadores pagan televisión (y otros medios) para atraer y proporcionar clientes y para suministrar otros servicios con noticias y entretenimientos. La presentación, en ocasiones, poco halagadora de los hombres de negocios (útil probablemente para recuperar la credibilidad perdida a causa de la publicidad) expresa, simplemente, el hecho de que la televisión sirve a sus clientes de negocios mediante el suministro y no con el halago.

Cuando muchos millones de dólares de ingresos dependen de un solo punto en la evaluación, hay muy pocos grados de libertad para preocuparse por el ego o para atender otras muchas presiones. La competencia para conseguir la máxima audiencia posible al mínimo coste significa que hay que esforzarse en pos de los reclamos más amplios y convencionales, difuminando los conflictos agudos, mezclando y compensando perspectivas competitivas y presentando las imágenes divergentes y desviadas como algo que casi siempre hay que evitar, temer o suprimir. En caso contrario, no importa lo sesgada o descentrada que pueda ser una escena; tiene que ser "compensada" por manifestaciones más «extremas", a ser posibles de «ambos.polos», para que su presentación parezca más "objetiva", «moderada" y más adecuada para la comercialización masiva. 
Estas funciones y presiones institucionalizadas sugieren el cultivo de presentaciones y orientaciones relativamente «moderadas» o de «centro». Hipótesis más específicas pueden surgir de los resultados del análisis de estas características y de la dinámica del sistema televisivo de mensajes y pueden ser relevantes para el cultivo de estas orientaciones.

Nuestro resumen de resultados está basado en el banco de datos del sistema de mensajes de Indicadores Culturales (a no ser que se diga expresamente lo contrario) y se centra en la programación de los canales de máxima audiencia. El mundo representado en el tiempo de máxima audiencia, tal como lo ve el televidente medio, está animado por presentaciones vívidas e intimas de más de 300 personajes principales por semana, la mayoría del tipo dramático, y por la aparición semanal de sus actividades dramáticas.

Aunque ese mundo pueda parecer convencional y «normal», está, de becho, lejos de cualquier realidad que no sean los valores de consumo y el poder social.

La curva de los gastos de consumo, a diferencia de la renta, presenta un abultamiento con el estatus de la clase media, así como con la edad madura. A pesar del hecho de que casi la mitad de la renta nacional corresponde al $20 \%$ de mayor nivel de la población real, el mito de la clase media como norma del perfecto americano domina el mundo de la televisión. Casi 7 de cada 10 personajes televisivos se sitúan en la clase media-media dentro de un sistema de clasificación de cinco niveles. La mayoría son profesionales y directivos. Los trabajadores industriales y de servicios representan el $67 \%$ del total de los americanos pero solamente ocupan el $10 \%$ de los personajes televisivos. Estas características del mundo de la máxima audiencia de la televisión debería cultivar una autodesignación de clase media o de renta «media» entre los televidentes.

Los hombres sobrepasan a la mujeres al menos en la proporción de tres a uno. La mayoría de las mujeres dedican sus cuidados a los hombres o realizan tareas domésticas (manejan electrodomésticos) y son más jóvenes (pero envejecen más rápido) que los hombres con los que se relacionan. La infrarrepresentación en el mundo de la televisión sugiere el cultivo de la aceptación por parte de los televidentes de un número más limitado de oportunidades vitales, una gama más limitada de actividades y unas imágenes más rígidamente estereotipadas que las existentes para los tipos sociales y dramáticos dominantes y más completamente representados.

Los jóvenes (menores de 18) representan un tercio y la gente anciana (mayores de 65) un quinto de la proporción que realmente les corresponde en la población. Los negros que aparecen en la televisión representan tres cuartas partes y los hispanos un tercio de la cuota que les corresponde en la población de EE.UU., y los personajes que los representan son, en número desproporcionado, de escasa importancia. Sólo un programa, "Hawai 5-0" concretamente, puede caer en una sobrerrepresentación de orientales, pero, de nuevo, como personajes de escasa importancia. Un estudio realizado por Weigel y otros (17) muestra que mientras que los negros aparecen en muchos programas y anuncios, raramente lo hacen en compañia de blancos e interactúan con estos últimos en tan sólo alrededor de un $2 \%$ del tiempo total de aparición de seres humanos. La sobrerrepresentación prominente y estable de varónes acomodados en la plenitud de la vida domina el tiempo de máxima audiencia. La demografía general 
de la televisión se parece más a la realidad de las pautas de consumo que al censo de los EE.UU. $(9,10)$. Estos hechos y la dinámica de la vida sugieren el cultivo entre los televidentes de un punto de vista relativamente estrecho respecto a los derechos de las mujeres y de las minorías.

El Estado, en el mundo de máxima audiencia, actúa, en la mayoria de los casos, para rechazar amenazas a la ley y al orden en un mundo mezquino y peligroso.

Hacer cumplir la ley de ese mundo supone recurrir, aproximadamente, a tres veces más personajes que los que representan a los trabajadores de los sectores industriales y de servicios. El típico espectador de programas de máxima audiencia de una semana media puede ver representaciones realistas y a menudo íntimas (pero habitualmente no verídicas con respecto a la vida real) de la vida y trabajo de 30 oficiales de policía, 7 abogados y 3 jueces, pero solamente un ingeniero y un científico y muy pocos trabajadores industriales. Casi todo el mundo parece estar confortablemente instalado en una renta «media» o formar parte de la "clase media».

Sin embargo las amenazas abundan. El delito en la programación de máxima audiencia es 10 veces más habitual que en el mundo real. Más de la mitad de todos los personajes principales están implicados en una media de cinco a seis actos de violencia física directa por hora. No obstante, el dolor, el sufrimiento y la asistencia médica raramente aparecen como consecuencia de este torbellino. La violencia simbólica demuestra poder; muestra victimización, no sólo agresión, daño pero no terapia; muestra quién puede salirse con la suya, en qué cosas y contra quién. Los varones blancos, dominantes, en la plenitud de la vida, alcanzan el puesto más alto en la «escala de seguridad»: es más probable que sean victimazadores que víctimas. A la inversa, las mujeres jóvenes, viejas o pertenecientes a minorías, así como los jóvenes, tienen mayor probabilidad de ser víctimas que de ser victimizadores en los conflictos violentos.

¿Cuáles podrian ser las «respuestas televisivas» relevantes para las orientaciones políticas?

La demografía deformada del mundo televisivo cultiva algunos conceptos inicuos de las normas de la vida social. Excepto entre aquellos más tradicionales o sesgados, la observación de la televisión tiende a ir acompañada de prejuicios más fuertes acerca de las mujeres y de los ancianos $(9,10,12,14)$. Los niños saben más de ocupaciones poco comunes, que aparecen frecuentemente en la televisión, que acerca de empleos comunes que rara vez se muestran en la pantalla (4). La observación de la televisión aumenta la evaluación de confianza otorgada a los médicos (16) pero disminuye la otorgada a los cientificos, especialmente en grupos que, por otra parte, son los que más los apoyan (8).

Los estudios de cultivo confirman los resultados según los cuales ver televisión tiende a elevar las percepciones de riesgo y peligro y a mantener un exagerado sentido de desconfianza, vulnerabilidad e inseguridad. Hemos encontrado también que la jerarquía de poder de los niveles relativos de victimización de los programas de máxima audiencia cultiva jerarquías similares de temor a la victimización en el mundo real entre los espectadores. Aquellos espectadores pertenencientes a grupos minoritarios que se contemplan a sí mismos más a menudo en las categorías que llevan la peor 
parte en los encuentros violentos en televisión, llegan a sentir mayor apresión hacia la posibilidad de su propia victimización que los consumidores ligeros de los mismos grupos (13).

Cabe esperar, pues, que el mundo mezquino y peligroso de televisión contribuya a la receptividad hacia las medidas represivas y a las «soluciones» y posiciones aparentemente simples, duras y directas. Al mismo tiempo, sin embargo, el contexto general de los valores convencionales y de las gratificaciones del consumidor, con sus exigencias de finales felices y satisfacción material, puede sugerir un sentido de derecho de acceso a los bienes y servicios, creando así un conflicto de perspectivas.

Así, se puede esperar el cultivo de la preferencia por orientaciones políticas "de centro" junto a supuestos diferentes y a veces contradictorios. Es muy probable que estos supuestos incluyan nociones demográficamente sesgadas, socialmente rígidas y preñadas de desconfianza, y a menudo excesivamente ansiosas o represivas, pero al mismo tiempo con amplias expectativas cada vez mayores de servicios económicos y de progreso material, incluso entre aquéllos que tradicionalmente no comparten estos puntos de vista.

Como la mayor parte de nuestra discusión se centra en las diferencias que existen entre televidentes duros, medios y ligeros, los cuales pertenecen a grupos que por otra parte son comparables, en las "respuestas televisivas" que dan, sería útil describir estos grupos.

Los análisis presentados aquí utilizan datos procedentes de la Encuesta Social General (ESG) del Centro de Investigación de Opinión Nacional (National Opinion Research Center) de 1975, 1977, 1978 y 1980. Alrededor de 1.500 encuestados tomaron parte en entrevistas personales de una hora de duración cada año, para un total de 6.020 encuestas ${ }^{7}$. Para los propósitos del análisis los encuestados han sido divididos en televidentes ligeros $(24,6 \%)$, aquellos que afirmaron ver televisión una media diaria inferior a las 2 horas; televidentes medios (45,3\%), los que decían verla 2 ó 3 horas y televidentes duros $(30,1 \%)$, los que decía verla más de cuatro horas diarias ${ }^{8}$.

Las diferencias en la cantidad de horas ante la televisión guardan, desde luego, relación con el modo en que vive la gente. El segmento de televidentes duros de la población incluye un número desproporcionado de mujeres, jóvenes y viejos, personas sin enseñanza superior y personas de bajos ingresos (véase la Tabla 1). A la inversa, comparativamente más hombres y personas de media edad, con enseñanza universitaria y renta más elevada tienden a ser televidentes ligeros ${ }^{9}$.

Es evidente, por tanto, que las sencillas comparaciones de televidentes duros, medios y ligeros llevan consigo algo más que la televisión. Para poder aislar la contribución independiente de la exposición a la televisión al cultivo de las orientaciones políticas, es necesario controlar otros factores y comparar diferencias relacionadas con el grado de exposición en subgrupos relativamente homogéneos. Todos los resultados citados en este artículo incluyen tales controles. Las diferencias entre subgrupos existentes dentro de cada grupo de televidentes nos permite especificar tanto la dinámica común como la diferencial de la exposición a la televisión ${ }^{10}$. 
TABLA I

Relación entre tiempo de exposición a la televisión y variables demográficas

\begin{tabular}{|c|c|c|c|c|c|c|}
\hline & \multicolumn{3}{|c|}{$\begin{array}{l}\text { Exposición a } \\
\text { la televisión }\end{array}$} & \multirow{2}{*}{ Gamma } & \multirow{2}{*}{$\stackrel{\mathbf{r}}{\text { Simple }^{b}}$} & \multirow{2}{*}{$\begin{array}{c}r \\
\text { parcial } \\
44^{\circ} \text { orden }\end{array}$} \\
\hline & $\underset{\%}{\text { Ligera }}$ & $\underset{\%}{\text { Media }}$ & $\underset{\%}{\text { Dura }}$ & & & \\
\hline \multicolumn{7}{|l|}{ Sexo } \\
\hline $\begin{array}{l}\text { Hombres }(\mathrm{N}=2638) \\
\text { Mujeres }(\mathrm{N}=3352)\end{array}$ & $\begin{array}{l}50 \\
50\end{array}$ & $\begin{array}{l}46 \\
54\end{array}$ & $\begin{array}{l}37 \\
63\end{array}$ & $.16^{*+*+4}$ & $.12^{2 * 4}$ & $.09: \%$ \\
\hline \multicolumn{7}{|l|}{ Edad } \\
\hline $\begin{array}{l}18-29(\mathrm{~N}=1531) \\
30-54(\mathrm{~N}=2598) \\
\text { A partir de } 55(\mathrm{~N}=1834)\end{array}$ & $\begin{array}{l}24 \\
51 \\
25\end{array}$ & $\begin{array}{l}24 \\
46 \\
30\end{array}$ & $\begin{array}{l}31 \\
34 \\
36\end{array}$ & .03 & .02 & $-.06^{* * * 5}$ \\
\hline \multicolumn{7}{|l|}{ Educación } \\
\hline $\begin{array}{l}\text { Sin estudios superiores } \\
(\mathrm{N}=4077) \\
\text { Con estudios superiores } \\
(\mathrm{N}=1893)\end{array}$ & $\begin{array}{l}54 \\
46\end{array}$ & $\begin{array}{l}67 \\
33\end{array}$ & $\begin{array}{l}82 \\
18\end{array}$ & $-.38^{* \infty}$ & $-.19 \div \div \%$ & $-.14^{2 * t ; 4}$ \\
\hline Ingresos & & . & & & & \\
\hline $\begin{array}{l}\text { Bajos }(N=2060) \\
\text { Medios }(N=1971) \\
\text { Altos }(N=1543)\end{array}$ & $\begin{array}{l}31 \\
35 \\
35\end{array}$ & $\begin{array}{l}33 \\
37 \\
30\end{array}$ & $\begin{array}{l}49 \\
33 \\
18\end{array}$ & $-.23 *$ & $-.19 \%$ & $-.12^{* * * *}$ \\
\hline \multicolumn{7}{|l|}{ Hábitat } \\
\hline $\begin{array}{l}\text { Urbano }(\mathrm{N}=2618) \\
\text { No urbano }(\mathrm{N}=3372)\end{array}$ & $\begin{array}{l}45 \\
55\end{array}$ & $\begin{array}{l}43 \\
57\end{array}$ & $\begin{array}{l}43 \\
57\end{array}$ & .03 & -.02 & -.02 \\
\hline
\end{tabular}

En este artículo refinamos y aplicamos el paradigma de sobre inclusión a las orientaciones políticas.

Avanzaremos e ilustraremos algunas proposiciones sobre la contribución de la televisión a la autoidentificación política y de clase. Examinaremos la dinámica política de la televisión a través del análisis de las posiciones de televidentes duros y ligeros de tendencias políticas diferentes, controlando simultáneamente un amplio espectro de otras influencias y de otros factores.

La afiliación política a un partido está tradicionalmente relacionada con el estatus social. Por tanto, no es sorprendente que entre los televidentes duros, que tienden a tener bajo estatus, encontremos más demócratas que entre los televidentes ligeros ( $45 \%$ frente a $35 \%$ ), mientras que un número mayor de televidentes ligeros que de televidentes duros son independientes ( $41 \%$ frente a $34 \%$ ) y republicanos ( $24 \%$ frente a $21 \%)^{11}$. Veremos, sin embargo, que la televisión modifica el significado social y político de estas y otras etiquetas convencionales. 
Un ejemplo de esta transformación es el desdibujamiento de las líneas de clase y la autoajustada «tendencia a la media» en las diferencias de renta. La Tabla 2 y la Figura 1 muestran que los encuestados con bajo nivel socioeconómico (SES) tienen una mayor probabilidad de autoatribuirse la etiqueta de «clase trabajadora» - pero sólo cuando son televidentes ligeros-. Los televidentes duros encuestados del mismo grupo de bajo estatus piensan de sí mismos que son "clase trabajadora» con una probabilidad significativamente menor que sus equivalentes en el grupo de televidentes ligeros, a la vez que es más probable que afirmen pertenecer a la «clase media». La experiencia de la televisión parece contrarrestar otras circunstancias a la hora de pensar en la propia clase. Es un disuasor especialmente poderoso de la conciencia de clase trabajadora.

Los televidentes de SES medio muestran el menor sentido de distinción de clase en los diferentes niveles de exposición a la televisión. Están ya «dentro" de la corriente dominante. El grupo de SES alto, sin embargo, igual que el grupo de SES bajo, presenta una pauta de respuesta que está fuertemente asociada con la cantidad de exposición a la televisión. El número de televidentes duros de alto SES que se consideran a sí mismos pertenecientes a la "clase trabajadora" es mayor que el de televidentes ligeros de alto SES ${ }^{12}$. La exposición a la televisión tiende a desdibujar las distinciones de clase y hace que los televidentes duros con mayor nivel de renta piensen de símismos que son simple clase trabajadora de renta media.

\section{FIGURA 1}

Bajos en status socio-económico/ingresos

Porcentaje de sujetos que se consideran:

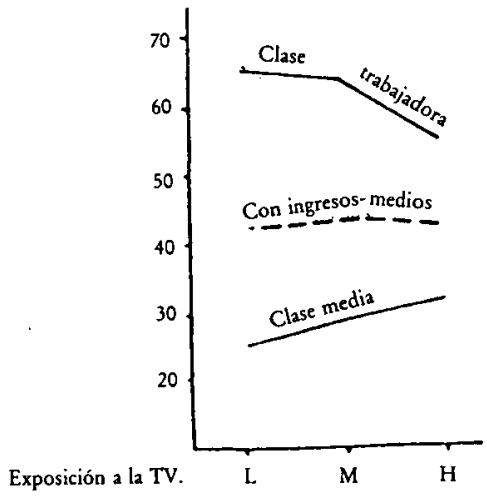

L: Consumidores ligeros

M: Consumidores medios

Altos en status socio-económico/ingresos

\section{Porcentaje de sujetos que se consideran:}

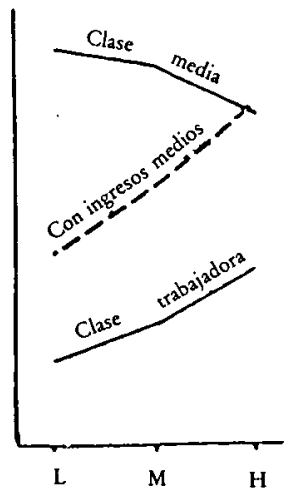

$\mathrm{H}$ : Consumidores duros

Autodesignaciones en clase e ingresos, por exposición a la televisión, en grupos de estatus e ingresos diferenciados de acuerdo con criterios objetivos.

Estos procesos se manifiestan claramente cuando relacionamos la exposición a la televisión con etiquetas de relevancia política directa. Usamos una designación de tendencia política relativamente general y presumible- 
TABLA II

Relación entre tiempo de exposición a la televisión y clase social subjetiva y tendencia a calificar de medios los ingresos familiares

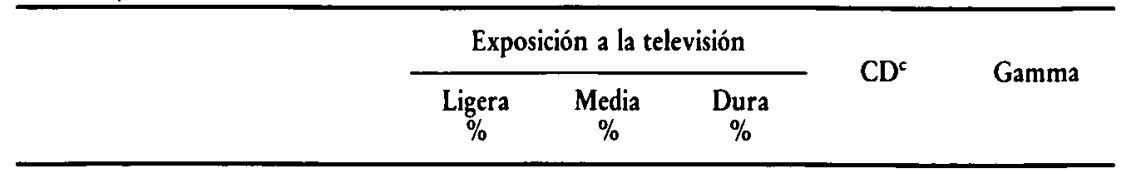

Clase social subjetiva ${ }^{a}$ por estatus socioeconómico (SES) real $(\mathrm{N}=5239)$

SES bajo

Clase trabajadora

Clase media

SES medio

Clase trabajadora

Clase media

SES alto

\section{Clase trabajadora}

Clase media

Porcentaje que considera «medios" sus ingresos familiares, de acuerdo con los ingresos familiares reales $(\mathrm{N}=5541)$

\section{- de $10.000 \$$}

Entre 10 y $20.000 \$$

Más de $20.000 \$$

$\begin{array}{rrrrr}65 & 64 & 55 & -10 & .06 * \\ 25 & 28 & 32 & +7\end{array}$

$\begin{array}{rrrrr}55 & 58 & 55 & 0 & -.07 * \\ 42 & 39 & 38 & -4 & \end{array}$

$\begin{array}{lllll}25 & 29 & 36 & +11 & -.14^{3 \% *}\end{array}$

$\because \mathrm{p}<.05$
$\because \mathrm{p}<.001$

2 Debido al bajo número de casos, se han omitido las respuestas de los grupos *superior» e einferior».

b Basado en la tricotomización de puntuaciones factoriales ponderadas en educación, ingresos y prestigio ocupacional.

c CD: Diferencial de Cultivo: porcentaje de consumidores duros que dan la respuesta en cuestión, menos porcentaje de consumidores ligeros que dan esa misma respuesta.

mente estable, la que presentaba la mayor probabilidad de estructurar un recorrido de actitudes y posiciones políticas: las autodesignaciones «liberal», «moderado» y «conservador» ${ }^{13}$. Suponíamos que los encuestados de la ESG y, en efecto, la mayoría de nosotros, sitúan las posiciones políticas sobre un continuo desde liberal hasta conservador ( $\mathrm{e}$ incluso más lejos en ambas direcciones) debido, en parte, al uso común y generalmente aceptado de estos términos en el discurso interpersonal y de los medios de comunicación. Consecuentemente, a diferencia de muchas cosas sobre las que se podía haber preguntado a los encuestados, creemos que estas autodesignaciones existían anteriormente y no se crean en la respuesta a la situación de entrevista.

La tabla 3 muestra el porcentaje de televidentes ligeros en cada categoría de tendencia política y la dispersión del porcentaje entre ellos y los televidentes duros, teniendo en cuenta en ambos casos las clasificaciones demográficas y la afiliación al partido. La relación más general entre exposi- 
TABLA III

Relación entre tiempo de exposición a la televisión y autodesignación politica $(N=5691)$

\begin{tabular}{|c|c|c|c|c|c|c|c|c|c|}
\hline & \multicolumn{9}{|c|}{ PORCENTAJE QUE SE CONSIDERAN A SI MISMOS: } \\
\hline & \multicolumn{3}{|c|}{ Liberales } & \multicolumn{3}{|c|}{ Moderados } & \multicolumn{3}{|c|}{ Conservadores } \\
\hline & $\% L^{2}$ & $\mathrm{CD}^{\mathrm{b}}$ & Gamma & $\% \mathbf{L}$ & CD & Gamma & $\% \mathbf{L}$ & $\mathrm{CD}$ & Gama \\
\hline TOTAL & 31 & -3 & $-.04 *$ & 33 & +12 & $.15 \%$ & 36 & -8 & $-.12^{2 * x+r}$ \\
\hline \multicolumn{10}{|l|}{ Control por: } \\
\hline \multicolumn{10}{|l|}{ Sexo } \\
\hline $\begin{array}{l}\text { Hombres } \\
\text { Mujeres }\end{array}$ & $\begin{array}{l}33 \\
29\end{array}$ & $\begin{array}{l}-1 \\
-3\end{array}$ & $\begin{array}{l}-0.1 \\
-.05\end{array}$ & $\begin{array}{l}30 \\
36\end{array}$ & $\begin{array}{r}+8 \\
+12\end{array}$ & $\begin{array}{l}.11^{1 * * *} \\
.15^{* * * 4}\end{array}$ & $\begin{array}{l}38 \\
35\end{array}$ & $\begin{array}{l}-8 \\
-9\end{array}$ & $\begin{array}{l}-.10^{* * 4} \\
-.13^{* * *}\end{array}$ \\
\hline \multicolumn{10}{|l|}{ Edad } \\
\hline $\begin{array}{l}\text { Menos de } 30 \\
30-54 \\
\text { A partir de } 55\end{array}$ & $\begin{array}{l}45 \\
29 \\
20\end{array}$ & $\begin{array}{l}-7 \\
-5 \\
+3\end{array}$ & $\begin{array}{l}-.09 * \\
-.09 * \\
.07\end{array}$ & $\begin{array}{l}30 \\
32 \\
39\end{array}$ & $\begin{array}{r}+13 \\
+14 \\
+6\end{array}$ & $\begin{array}{l}.18^{* * *} \\
.18^{* * *} \\
.07^{*}\end{array}$ & $\begin{array}{l}26 \\
39 \\
41\end{array}$ & $\begin{array}{l}-7 \\
-8 \\
-9\end{array}$ & $\begin{array}{l}-.13^{* * 4} \\
-.11^{1 * * 8} \\
-.12^{* *}\end{array}$ \\
\hline \multicolumn{10}{|l|}{ Educación } \\
\hline $\begin{array}{l}\text { Sin educación superior } \\
\text { Con educación superior }\end{array}$ & $\begin{array}{l}24 \\
38\end{array}$ & $\begin{array}{l}+2 \\
-1\end{array}$ & $\begin{array}{r}.04 \\
-.05\end{array}$ & $\begin{array}{l}41 \\
25\end{array}$ & $\begin{array}{l}+6 \\
+8\end{array}$ & $\begin{array}{l}.08^{* \%} \\
.13 \% \div \%\end{array}$ & $\begin{array}{l}35 \\
37\end{array}$ & $\begin{array}{l}-8 \\
-7\end{array}$ & $\begin{array}{l}-.12^{* * *} \\
-.07 *\end{array}$ \\
\hline \multicolumn{10}{|l|}{ Ingresos } \\
\hline $\begin{array}{l}\text { Bajos } \\
\text { Medios } \\
\text { Altos }\end{array}$ & $\begin{array}{l}34 \\
29 \\
31\end{array}$ & $\begin{array}{l}-4 \\
-3 \\
-5\end{array}$ & $\begin{array}{l}-.06 \\
-.04 \\
-.10^{*}\end{array}$ & $\begin{array}{l}35 \\
35 \\
30\end{array}$ & $\begin{array}{r}+8 \\
+13 \\
+14\end{array}$ & $\begin{array}{l}.11^{* * *} \\
.16^{* * * * 4} \\
.19^{* * * *}\end{array}$ & $\begin{array}{l}31 \\
36 \\
39\end{array}$ & $\begin{array}{r}-4 \\
-10 \\
-9\end{array}$ & $\begin{array}{l}-.07 * \\
-.14^{* * * *} \\
-.10^{* * *}\end{array}$ \\
\hline \multicolumn{10}{|l|}{ Hábitat } \\
\hline $\begin{array}{l}\text { Urbano } \\
\text { No Urbano }\end{array}$ & $\begin{array}{l}36 \\
26\end{array}$ & $\begin{array}{l}-3 \\
-2\end{array}$ & $\begin{array}{l}-.04 \\
-.04\end{array}$ & $\begin{array}{l}31 \\
34\end{array}$ & $\begin{array}{r}+9 \\
+14\end{array}$ & $\begin{array}{l}.12^{* * *} \\
.17^{* * * *}\end{array}$ & $\begin{array}{l}33 \\
40\end{array}$ & $\begin{array}{r}-6 \\
-12\end{array}$ & $\begin{array}{l}-.09 \% * \\
-.15^{*} \%\end{array}$ \\
\hline \multicolumn{10}{|l|}{ Afiliación a partido } \\
\hline $\begin{array}{l}\text { Demócratas } \\
\text { Independientes } \\
\text { Republicanos }\end{array}$ & $\begin{array}{l}37 \\
34 \\
16\end{array}$ & $\begin{array}{l}-6 \\
-7 \\
+5\end{array}$ & $\begin{array}{l}-.06^{*} \\
-.11^{* *} \\
.11^{* *}\end{array}$ & $\begin{array}{l}37 \\
33 \\
29\end{array}$ & $\begin{array}{r}+7 \\
+14 \\
+13\end{array}$ & $\begin{array}{l}.08^{* \%} \\
.19^{* * \%} \\
.18^{* * \%}\end{array}$ & $\begin{array}{l}27 \\
33 \\
55\end{array}$ & $\begin{array}{r}-2 \\
-7 \\
-18\end{array}$ & $\begin{array}{l}-.03 \\
-.11^{* *} \\
-.23^{* * 4}\end{array}$ \\
\hline $\begin{array}{l}* \mathrm{p}<.05 \text { (tau) } \\
\mathrm{p}<0.1 \text { (tau). } \\
\mathrm{p}<.001 \text { (tau) }\end{array}$ & & & & . & & & & & \\
\hline
\end{tabular}

ción a la televisión y tendencia política es que, de manera significativa, un número mayor de televidentes duros que de televidentes ligeros, en todos los subgrupos, se llaman a sí mismos moderados y, también de manera significativa, un número menor se llaman a sí mismos conservadores ${ }^{14}$. El número de liberales también declina ligeramente entre los televidentes duros, excepto cuando son los menos liberales (p. ej. entre los Republicanos). La figura 2 ilustra la absorción de las tendencias divergentes y la mezcla de las distinciones políticas que realiza la "corriente dominante de televisión»" 
En apariencia, la sobreinclusión parece ser un «moderador» -incluso un «liberador»- de tendencias políticas y de otro tipo. Después de todo, a medida que la exposición a la televisión aumenta, el porcentaje de conservadores disminuye significativamente dentro de cada grupo (exceptuando a los Demócratas), y las relaciones entre la cantidad de exposición a la televión y el porcentaje de liberales son, por lo general, más tenues. Sin embargo, un examen más detallado de las posiciones reales elegidas como respuesta a las preguntas sobre problemas políticos tales como minorías, derechos civiles y personales, libertad de expresión, economia, etc., muestra que la corriente dominante no siempre significa "el punto medio".

Se plantearon ocho preguntas sobre las actitudes hacia los negros en, al menos, dos de los cuatro años de la ESG que aqui se analizan, y a través de ellas se evaluó explícitamente el deseo de los encuestados de mantener a negros y blancos separados.

Las preguntas incluyen «jpiensa que los estudiantes blancos y negros deben ir a la misma escuela o a escuelas separadas?" y "¿piensa que debería haber leyes contra el matrimonio entre negros y blancos?». La tabla 4 re-

\section{FIGURA 2}

Porcentaje que se consideran:

DEMOCRATAS

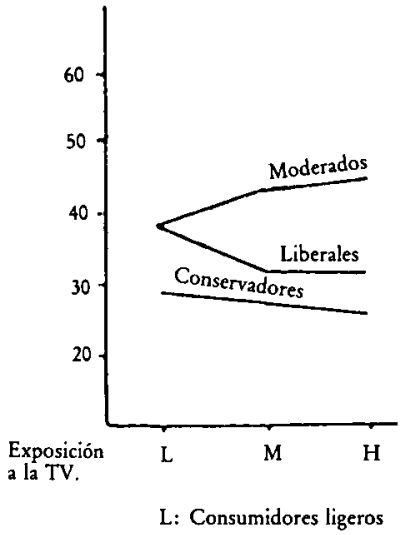

INDEPENDIENTES

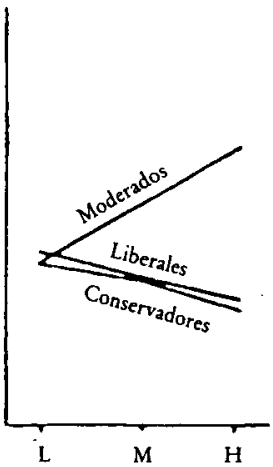

M: Consumidores medios
REPUBLICANOS

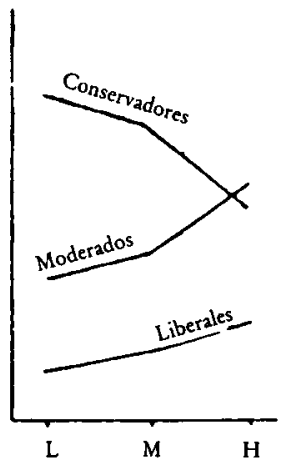

$\mathrm{H}$ : Consumidores duros.

Autodesignación politica por tiempo de exposición a la televisión, de acuerdo con categorias de partido.

sume las relaciones entre cantidad de exposición a la televisión y estos ocho ítems, para los autodesignados liberales, moderados y conservadores. Los televidentes liberales ligeros son siempre los que tienen menor probabilidad de avalar afirmaciones segregacionistas. Es interesante constatar cómo los televidentes moderados y conservadores ligeros están muy cercanos entre sí; en más de un caso, los televidentes moderados ligeros tienen una probabilidad algo mayor de apoyar la segregación racial que los conservadores ligeros.

Más importante aún, las asociaciones entre exposición a la televisión y 


\section{TABLA IV}

Sintesis de relaciones entre tiempo de exposición a la televisión y actitudes hacia los negros, controlando la autodesignación política (sólo blancos)

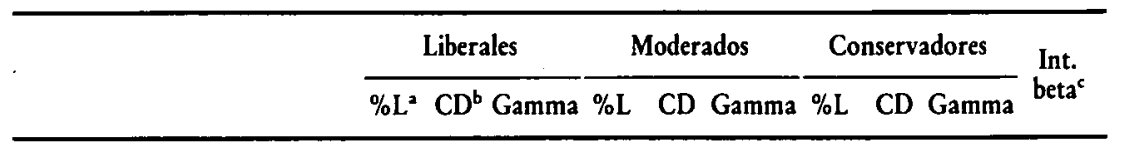

Porcentaje:

Favorable a las leyes contra el matrimonio interracial $\mathrm{N}=3716$ $13+22.38^{* * *} \quad 31+10 \quad .14^{* *} \quad 32+9 \quad .12^{* *} .15$

En desacuerdo si un negro fuera invitado a comer $(=2511)$ $\begin{array}{lllllllll}13+11 & .24 * * \% & 22 & +7 & .09 * & 26 & +7 & .10 * & .02\end{array}$

Decididamente de acuerdo: los negros no deberian entrar allí donde no son queridos $(\mathrm{N}=3715)$

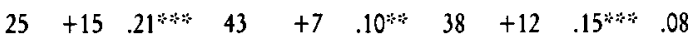

Decididamente de acuerdo: los blancos tienen derecho a vivir en barrios separados $(\mathrm{N}=2474)$

$\begin{array}{lllllllll}10+9 & .23 * & 14 & +8 & .15 * & 22 & +1 & .04 & .17 *\end{array}$

En contra de leyes para el régimen libre de residencia $(\mathrm{N}=3743)$

$43+12 \quad .15^{*} \quad 63 \quad-1-.03 \quad 70 \quad-1-.01 \quad .13^{* *}$

En contra de forzar la integración racial en las escuelas a través del transporte escolar $(\mathrm{N}=3670)$

Que no votaría si un negro se presentara como candidato a la Presidencia $(\mathrm{N}=3639)$

(1)

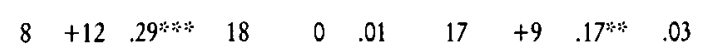

Que cree que blancos y negros deberían ir a escuelas separadas $(\mathrm{N}=2948)$

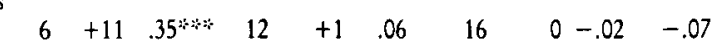

$\because \mathrm{p}<.05$

$\because \mathrm{p}<0.1$

$\forall *: p<.001$

a $\quad$ Porcentaje de consumidores ligeros que da la respuesta.

${ }^{b} \mathrm{CD}=$ Diferencial de Cultivo: Porcentaje de consumidores duros que da la respuesta, menos porcentaje de consumidores ligeros que lo hace.

${ }^{c}$ Interacción beta: Interacción del tiempo de exposición y autoubicación política con edad, sexo, educación, ingresos, hábitat y efectos principales de la exposición en la ecuación.

estas actitudes son marcadamente diferentes para liberales, moderados y conservadores. Los liberales, que son los que tienen menos probabilidad de sostener puntos de vista segregacionistas, muestran una asociación llamativa (y siempre significativa) entre cantidad de exposición a la televisión y el deseo de mantener a negros y blancos separados. Entre los moderados y conservadores, por el contrario, las relaciones entre exposición a la televisión y estas actitudes son más pequeñas e inconsistentes. (Cuatro de los términos de interacción son significativos, mostrando que los correlatos de la exposición elevada son sistemáticamente diferentes a través de las categorías políticas). Sobre la integración racial en las escuelas a través del transporte escolar, moderados y conservadores muestran incluso una asociación 
negativa significativa, indicando menos actitudes segregacionistas entre estos televidentes duros; he aquí un ejemplo de cómo la exposición a la televisión hace que, desde ambas direcciones, grupos divergentes se aproximen entre sí.

En general, estas pautas ilustran vívidamente la sobreinclusión. Hay, sin duda, algunas relaciones que traspasan estos límites, pero incluso ellas son marcadamente más débiles para moderados y conservadores. En general, estos datos muestran una convergencia y homogeneización de los televidentes duros a través de los grupos políticos.

Las diferencias entre liberales y conservadores -es decir, los efectos de la tendencia política sobre las actitudes hacia los negros-decrece entre los televidentes duros. Entre los televidentes ligeros, liberales y conservadores muestran una diferencia media de 15,4 puntos de porcentaje; pero, entre los televidentes duros, liberales y conservadores difieren en una media de sólo 4.6 puntos de porcentaje $(\mathrm{t}=4.54 \mathrm{p}<.01)$.

La figura 3 muestra la pauta de sobreinclusión para tres de estos ítems. En el primero, oposición a la integración racial en las escuelas a través del transporte escolar, podemos ver que los televidentes conservadores duros son más «liberales» y los televidentes liberales duros son más «conservadores» que sus respectivos equivalentes ligeros. En el segundo ejemplo, la oposición a las leyes de alojamiento abierto, la exposición a la televisión no está asociada con ninguna diferencia en las actitudes expresadas por los conservadores, pero entre los liberales vemos que la exposición elevada va acompañada de una probabilidad mayor de que esa oposición se presente. Finalmente, en respuesta a una pregunta sobre leyes contrarias a los matrimonios entre negros y blancos, encontramos que en todos los grupos los televidentes duros tienen mayor probabilidad de favorecer dichas leyes que

FIGURA 3

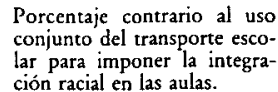

ción racial en las aulas.
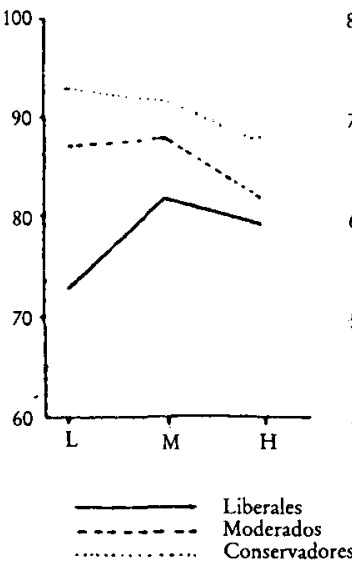

Porcentaje contrario a la libertad de alojamiento.

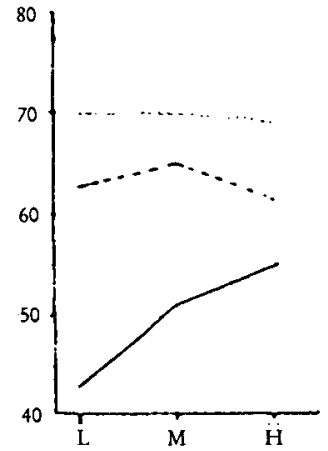

Porcentaje favorable a las layes contra el matrimonio in. terracial.

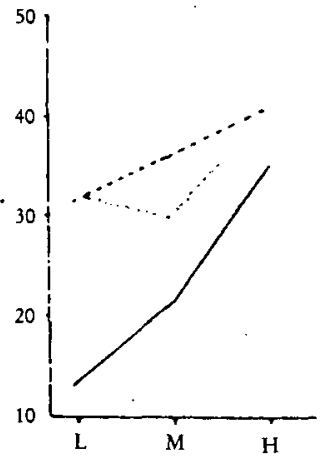

L: Consumidores ligeros

$\mathrm{M}$ : Consumidores medios

$\mathrm{H}$ : Conservadores duros 
los televidentes ligeros pertenecientes a las mismas categorías, pero esto es más pronunciado significativamente para los liberales.

En resumen, las respuestas de los televidentes liberales duros son perfectamente comparables a las de todos los moderados y conservadores y no hay mucha diferencia entre moderados y conservadores. La tendencia dominante de la televisión, por lo que respecta a las actitudes hacia los negros, se desplaza claramente hacia la derecha ${ }^{16}$.

Muchas de las más feroces batallas politicas de la última década se han librado sobre las «fronteras de la nación" - en torno a las denominadas cuestiones morales, las cuales han dividido claramente a las fuerzas liberales $y$ conservadoras.

Encontramos que los liberales se enfrentan a los conservadores por la propiedad, la moralidad e incluso la legalidad del comportamiento personal. Las luchas que incluyen la libertad de reproducción, los derechos de las minorías sexuales, y la enmienda de la igualdad de derechos han llegado a ser el centro de esa confrontación.

Nuestra visión de la televisión como una fuerza estabilizadora, que bus-

\section{TABLA V}

Relación entre tiempo de exposición a la televisión y actitudes hacia la conducta personal, controlando la autodesignación política

\begin{tabular}{|c|c|c|c|c|c|c|}
\hline & \multicolumn{3}{|c|}{$\begin{array}{l}\text { Exposición a } \\
\text { la televisión }\end{array}$} & \multirow{2}{*}{$\mathrm{CD}^{2}$} & \multirow{2}{*}{ Gama } & \multirow{2}{*}{$\begin{array}{l}\text { Int. } \\
\text { beta }{ }^{b}\end{array}$} \\
\hline & $\underset{\%}{\operatorname{Ligera}}$ & $\underset{\%}{\text { Media }}$ & $\underset{\%}{\text { Dura }}$ & & & \\
\hline \multicolumn{7}{|c|}{$\begin{array}{l}\text { Porcentaje de encuestados que } \\
\text { dicen que la homosexualidad } \\
\text { siempre está mal }(\mathrm{N}=2736)\end{array}$} \\
\hline $\begin{array}{l}\text { Liberales } \\
\text { Moderados } \\
\text { Conservadores }\end{array}$ & $\begin{array}{l}47 \\
71 \\
77\end{array}$ & $\begin{array}{l}54 \\
79 \\
81\end{array}$ & $\begin{array}{l}67 \\
77 \\
82\end{array}$ & $\begin{array}{r}+20 \\
+6 \\
+5\end{array}$ & $\begin{array}{l}.25^{* * *} \\
.08 \\
.09\end{array}$ & $-.19 \div \%$ \\
\hline \multicolumn{7}{|c|}{$\begin{array}{l}\text { En contra del aborto } \\
(N=5691)\end{array}$} \\
\hline $\begin{array}{l}\text { Liberales } \\
\text { Moderados } \\
\text { Conservadores }\end{array}$ & $\begin{array}{l}32 \\
45 \\
55\end{array}$ & $\begin{array}{l}38 \\
46 \\
47\end{array}$ & $\begin{array}{l}44 \\
51 \\
51\end{array}$ & $\begin{array}{r}+12 \\
+6 \\
-4\end{array}$ & $\begin{array}{l}.16^{* * * *} \\
.08^{* *} \\
-.05\end{array}$ & $-.18^{* * * *}$ \\
\hline \multicolumn{7}{|c|}{$\begin{array}{l}\text { En contra de legalizar el consu- } \\
\text { mo de marihuana }(N=4088)\end{array}$} \\
\hline $\begin{array}{l}\text { Liberales } \\
\text { Moderados } \\
\text { Conservadores }\end{array}$ & $\begin{array}{l}50 \\
72 \\
80\end{array}$ & $\begin{array}{l}56 \\
79 \\
84\end{array}$ & $\begin{array}{l}67 \\
79 \\
84\end{array}$ & $\begin{array}{r}+17 \\
+7 \\
+4\end{array}$ & $\begin{array}{l}.22^{* 4 \%} \\
.09 \\
.08\end{array}$ & $-.18 *$ \\
\hline $\begin{array}{rl}* p & p .05 \\
* & p<.01 \\
p & <.001\end{array}$ & & & & & & \\
\hline
\end{tabular}


ca atraer a la mayor audiencia posible ensalzando la «moderación» de la corriente dominante, nos lleva a esperar que los televidentes duros, una vez más, mostrarán una convergencia de actitudes en las cuestiones de moralidad personal. Esperamos encontrar próximos a los autodenominados moderados y conservadores, independientemente de la cantidad de exposición a la televisión, y a los televidentes liberales duros ocupando posiciones al lado de los moderados y conservadores.

La tabla 5 apoya nuestras predicciones ${ }^{17}$.

En el caso de actitudes sobre la homosexualidad, el aborto y la marihuana, hay una considerable dispersión entre los televidentes liberales lige-

FIGURA 4

Porcentaje que afirma que la
homosexualidad siempre «esta mal..
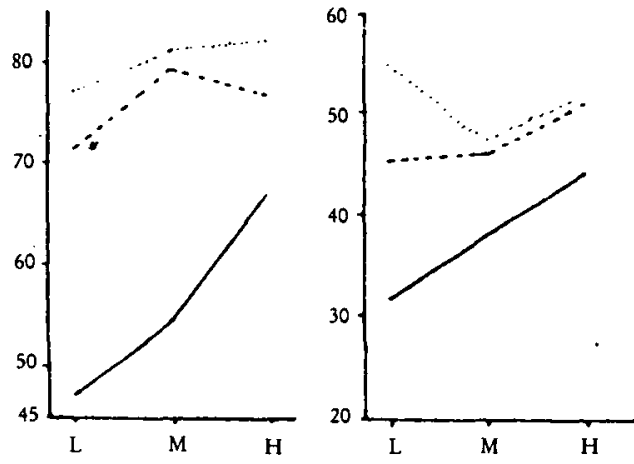

$\mathrm{L}:$ Consumidores ligeros

M: Consumidores medios

$\mathrm{H}$ : Consumidores duros
Porcentaje contrario a la legalización de la marihuana.

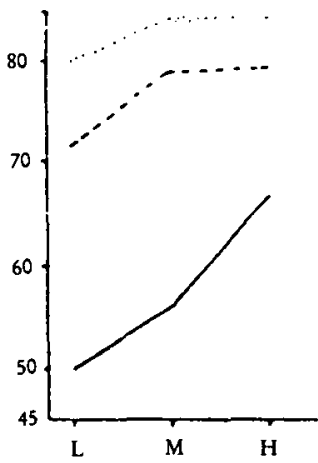

Exposición a la televisión y actitudes hacia la conducta personal, de acuerdo con la autodesignación política.

ros y los televidentes conservadores ligeros (una media de 28 puntos de porcentaje); es siempre mucho más probable que estos últimos opongan. Y, una vez más, las actitudes de los televidentes liberales y conservadores duros están mucho más cercanos (una media de 13 puntos de porcentaje; $t=16.6 \mathrm{p}<.01$ ), debido fundamentalmente a la diferencia entre los televidentes liberales duros y ligeros. (Todos los términos de interacción son significativos). En todos los casos, los autodesignados moderados están mucho más cerca de los conservadores que de los liberales (véase figura 4) ${ }^{18}$.

El estrechamiento del espectro politico se revela también en algunos hallazgos más explicitamente "politicos".

Independientemente de las razones y justificaciones, el anticomunismo se ha usado como la razón principal para la represión política desde el primer Terror Rojo de 1919-1920. Respuestas a diferentes preguntas de la ESG muestran la relación de la televisión con los sentimientos anticomunistas y con la tendencia a restringir la libertad de expresión ${ }^{19}$. 


\section{TABLA VI}

Relación entre tiempo de exposición a la televisión y actitudes hacia el comunismo y la libertad de expresión, controlando la autodesignación politica

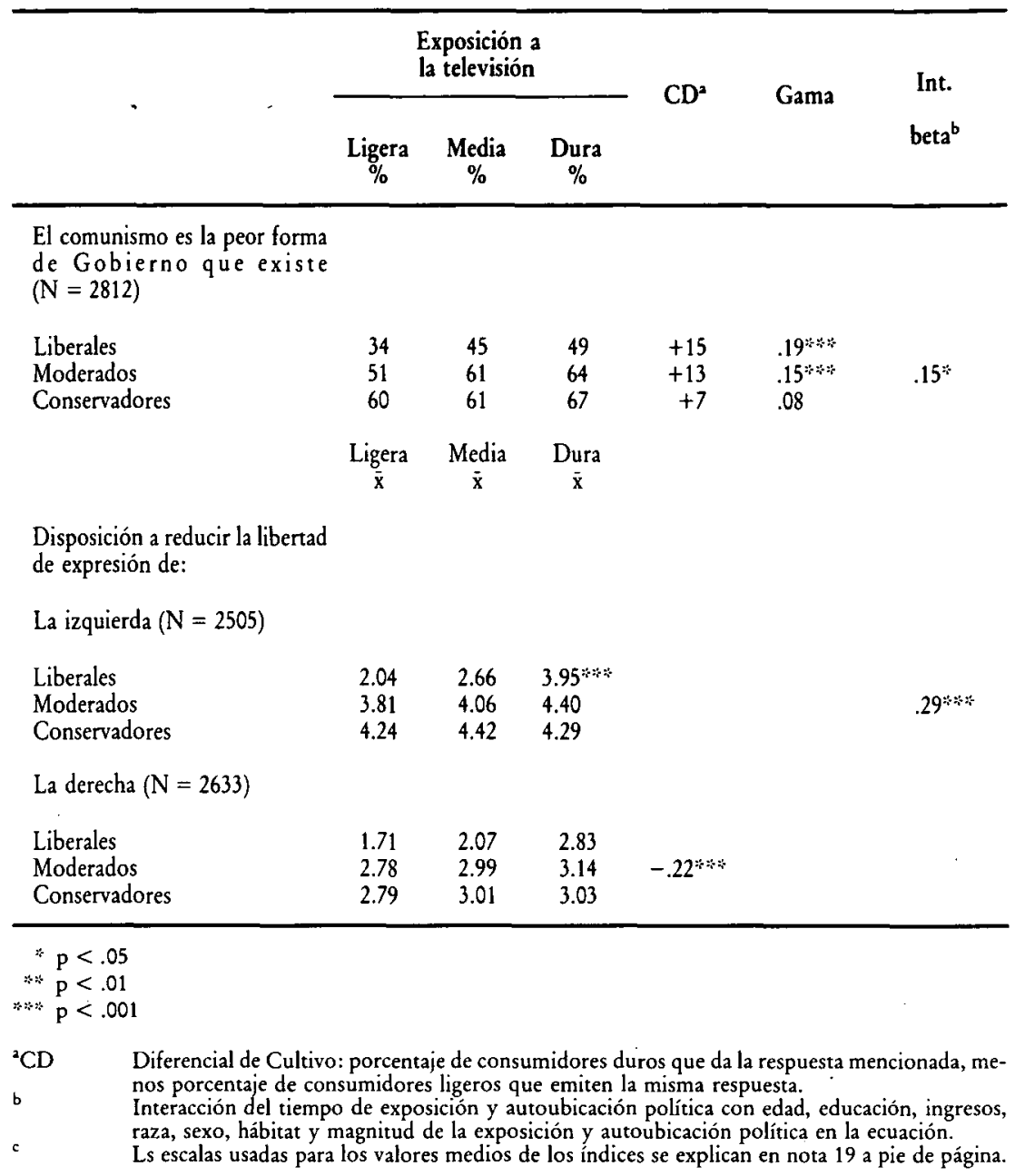

La tabla 6 muestra la pauta familiar (ilustrada en la figura 5). Cinco de cada diez televidentes moderados ligeros y seis de cada diez televidentes conservadores ligeros consideran el comunismo como «la peor forma (de gobierno) de todas». Los televidentes moderados y conservadores duros prácticamente están unidos en la condena del comunismo como el ««peor» con márgenes incluso más amplios (64 y $67 \%$ respectivamente). Pero la cantidad de exposición es lo que provoca la mayor diferencia entre los liberales: solamente un tercio de los televidentes liberales ligeros, frente a la mitad de los televidentes liberales duros, están de acuerdo con que el comunismo es "la peor forma de gobierno". (La interacción de la cantidad de exposición a la televisión con la autodesignación política es significativa por encima de todos los controles y efectos principales; beta $=-.15$, $\mathrm{p}<.05)$. 


\section{FIGURA 5}

Porcentaje que afirma que el comunismo es la peor forma de gobierno de todas.
Promedio de apoyo a las restricciones en la libertad de expresión.

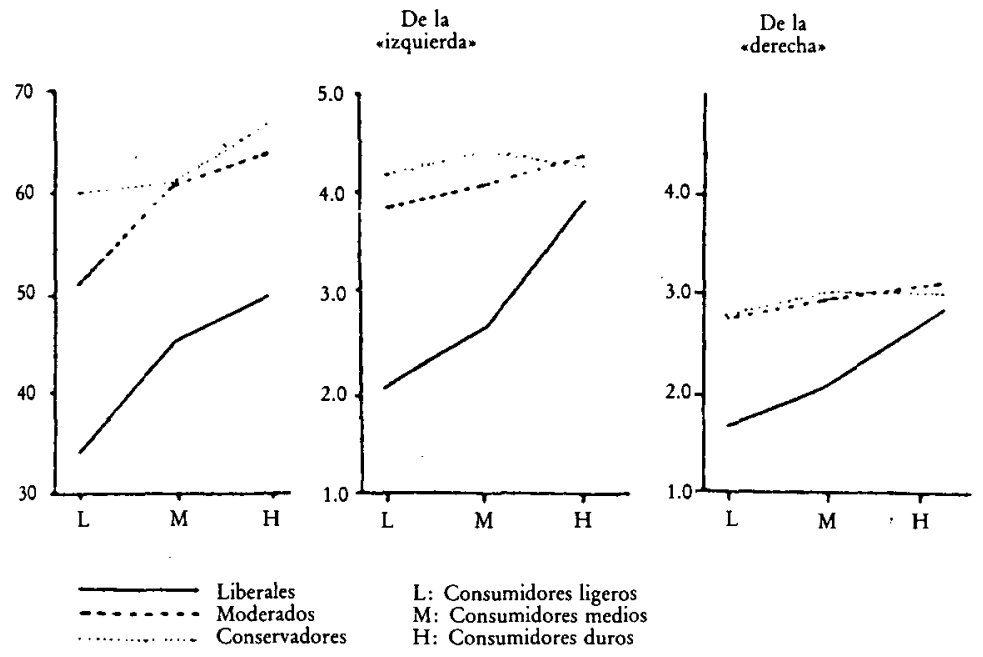

Exposición a la televisión y actitudes hacia el comunismo y la libertad de expresión, de acuerdo con la autodesignación política.

Las respuestas sobre la restricción de la libertad de expresión muestra pautas similares. Los televidentes duros de las tres denominaciones políticas tienen mayor probabilidad que sus equivalentes ligeros de estar de acuerdo con la restricción, bajo formas diversas, de los no conformistas de «izquierda» y «derecha». Hay poca diferencia entre conservadores y moderados. Pero, de nuevo, la diferencia más sorprendente está entre los televidentes liberales ligeros y duros.

En general, con respecto al anti-comunismo y a las restricciones de expresión política de la izquierda y la derecha, aquéllos que se denominan a sí mismos conservadores están en la «tendencia dominante de la televisión». Los que se consideran a sí mismos moderados se unen a los conservadores - o los superan- como televidentes duros. Los liberales desempeñan su rol tradicional de defensa de la pluralidad política y la libertad de expresión solamente cuando son televidentes ligeros. La sobreinclusión no sólo significa un estrechamiento de las diferencias políticas sino también una inclinación significativa del equilibrio político ${ }^{20}$.

Pero la tendencia política hacia la derecha no lo es todo. Como hemos señalado anteriormente, la televisión tiene una clientela comercial que, además de poder ser políticamente conservadora, tambien tiene una misión a realizar que requiere el cultivo de los valores y satisfacciones del consumidor, que apuntan en una dirección diferente.

Varias encuestas han documentado la tendencia de los encuestado a apoyar los servicios del gobierno que les benefician, mientras que adoptan posiciones cada vez más duras sobre impuestos, igualdad, delito y otros problemas que excitan ansiedades e inseguridades profundamente sentidas. Los 
medios de comunicación interpretaron (y los resultados de las elecciones parecían confirmarlo, al menos en los primeros años 80 ) esas posiciones intrínsecamente contradictorias como una «tendencia conservadora» (5). La televisión puede haber contribuido a esa tendencia de dos formas. Primero, comohan demostrado nuestros Perfiles de Violencia, los televidentes duros tienen un sentimiento más agudizado de vivir en un «mundo ruin", con peligros e inseguridades mayores que los grupos comparables de televidentes ligeros $(6,13)$. Segundo, aunque la televisión no lleve directamente a los televidentes a ser conservadores (de hecho los televidentes duros tienden a rechazar esa etiqueta) su corriente dominante de moderación aparente desplaza las actitudes políticas hacia posiciones conservadoras.

No obstante, cuando se examinan las posiciones sobre cuestiones económicas, emerge una pauta diferente, aunque quizá complementaria.

La televisión necesita atraer un amplio seguimiento para llevar a cabo su tarea principal de entregar al público comprador a sus patrocinadores. Le está menos permitido incluso que a la mayoría de los políticos pedir aus-

\section{TABLA VII}

Relación entre tiempo de exposición a la televisión y actitudes bacia la el gasto público, controlando la autodesignación política

\begin{tabular}{cccccc}
\hline & \multicolumn{3}{c}{$\begin{array}{c}\text { Exposición a } \\
\text { la televisión }\end{array}$} & & \\
\cline { 2 - 3 } & $\mathrm{CD}^{2}$ & Gama & Int. \\
\hline $\begin{array}{c}\text { Ligera } \\
\%\end{array}$ & $\begin{array}{c}\text { Media } \\
\%\end{array}$ & $\begin{array}{c}\text { Dura } \\
\%\end{array}$ & & & beta $^{b}$ \\
\hline
\end{tabular}

$\%$ que dice que se gasta dema-

siado en:

Sanidad $(\mathrm{N}=5478)$

Liberales

Moderados

Conservadores

$\begin{array}{rrrrrr}5 & 3 & 3 & -2 & -.16 & \\ 9 & 5 & 4 & -5 & -.12 & -15 * \% \\ 17 & 11 & 8 & -9 & -.25 & \end{array}$

Medio ambiente $(\mathrm{N}=5387)$

Liberales

Moderados

Conservadores

7
10

Ciudades $(\mathrm{N}=4983)$

Liberales

Moderados

Conservadores

Educación $(\mathrm{N}=4983$ )

Liberales

Moderados

Conservadores

Ayuda exterior

Liberales

Moderados

Conservadores

$31 \quad 28$

15

$\begin{array}{ll}+2 & .06 \\ -7 & -.14\end{array}$

$-.11 *$

.




\section{TABLA VII}

(Continuación)

\begin{tabular}{|c|c|c|c|c|c|c|c|}
\hline & & \multicolumn{3}{|c|}{$\begin{array}{l}\text { Exposición a } \\
\text { la televisión }\end{array}$} & \multirow{2}{*}{$\mathrm{CD}^{2}$} & \multirow{2}{*}{ Gama } & \multirow{2}{*}{$\begin{array}{l}\text { Int. } \\
\text { beta }^{b}\end{array}$} \\
\hline & & $\underset{\%}{\operatorname{Ligera}}$ & $\underset{\%}{\text { Media }}$ & $\underset{\%}{\text { Dura }}$ & & & \\
\hline \multicolumn{8}{|c|}{ Bienestar social $(\mathrm{N}=5454)$} \\
\hline $\begin{array}{l}\text { Liberales } \\
\text { Moderados } \\
\text { Conservadores }\end{array}$ & & $\begin{array}{l}48 \\
62 \\
71\end{array}$ & $\begin{array}{l}51 \\
61 \\
66\end{array}$ & $\begin{array}{l}43 \\
52 \\
58\end{array}$ & $\begin{array}{r}-5 \\
-10 \\
-13\end{array}$ & $\begin{array}{l}-.06 \\
-.15^{* \neq *} \\
-.17^{7 * *}\end{array}$ & -.06 \\
\hline \multicolumn{8}{|c|}{ Negros $(N=5276)$} \\
\hline $\begin{array}{l}\text { Liberales } \\
\text { Moderados } \\
\text { Conservadores }\end{array}$ & & $\begin{array}{l}19 \\
30 \\
35\end{array}$ & $\begin{array}{l}21 \\
28 \\
33\end{array}$ & $\begin{array}{l}17 \\
22 \\
29\end{array}$ & $\begin{array}{l}-2 \\
-8 \\
-6\end{array}$ & $\begin{array}{l}-.04 \\
-.13^{* *} \\
-.07^{*}\end{array}$ & -.06 \\
\hline \multicolumn{8}{|c|}{$\begin{array}{l}\% \text { que dice que se gasta dema- } \\
\text { siado poco en: }\end{array}$} \\
\hline \multicolumn{8}{|c|}{ Delincuencia $(N=5419)$} \\
\hline $\begin{array}{l}\text { Liberales } \\
\text { Moderados } \\
\text { Conservadores }\end{array}$ & & $\begin{array}{l}58 \\
69 \\
65\end{array}$ & $\begin{array}{l}66 \\
74 \\
70\end{array}$ & $\begin{array}{l}70 \\
77 \\
69\end{array}$ & $\begin{array}{r}+12 \\
+8 \\
+4\end{array}$ & $\begin{array}{l}.17^{* * 4} \\
.11^{* * \%} \\
.05\end{array}$ & $-.09 *$ \\
\hline \multicolumn{8}{|c|}{ Drogas $(N=5317)$} \\
\hline $\begin{array}{l}\text { Liberales } \\
\text { Moderados } \\
\text { Conservadores }\end{array}$ & & $\begin{array}{l}48 \\
57 \\
55\end{array}$ & $\begin{array}{l}58 \\
64 \\
56\end{array}$ & $\begin{array}{l}68 \\
67 \\
64\end{array}$ & $\begin{array}{r}+20 \\
+10 \\
+9\end{array}$ & $\begin{array}{l}.26^{* * *} \\
.12^{* * *} \\
.11^{* *}\end{array}$ & -.01 \\
\hline \multicolumn{8}{|c|}{ Armas $(N=5328)$} \\
\hline $\begin{array}{l}\text { Liberales } \\
\text { Moderados } \\
\text { Conservadores }\end{array}$ & $\cdot$ & $\begin{array}{l}18 \\
32 \\
41\end{array}$ & $\begin{array}{l}27 \\
35 \\
40\end{array}$ & $\begin{array}{l}31 \\
33 \\
41\end{array}$ & $\begin{array}{r}+13 \\
+1 \\
0\end{array}$ & $\begin{array}{l}.21^{* * * *} \\
.00 \\
.01\end{array}$ & $-.15^{* * *}$ \\
\hline $\begin{array}{l}\text { Exploración } \\
(N=5385)\end{array}$ & espacial & & & & & & \\
\hline $\begin{array}{l}\text { Liberales } \\
\text { Moderados } \\
\text { Conservadores }\end{array}$ & & $\begin{array}{l}20 \\
10 \\
18\end{array}$ & $\begin{array}{l}16 \\
10 \\
15\end{array}$ & $\begin{array}{r}10 \\
8 \\
9\end{array}$ & $\begin{array}{r}-10 \\
-2 \\
-9\end{array}$ & $\begin{array}{l}-.23^{* 2 * 4} \\
-.08 \\
-.21^{* x * x}\end{array}$ & .04 \\
\hline
\end{tabular}

\footnotetext{
$* p<.05$

* $\mathrm{p}<.01$

wis $p<.001$

${ }^{a} y{ }^{b}:$ Ver definiciones en Tabla 6.
}

teridad, denigrar los problemas populares básicos o recomendar el ahorro en vez de el gasto en bienes, servicios y seguridad. La misión esencial de la institución de la televisión, - la movilización de masas para el consumo- parecería aconsejar una postura económicamente popular e incluso populista.

Examinamos las pautas de respuesta a la pregunta sobre gasto del gobierno en 11 programas. Los resultados se muestran en la tabla 7. Hay sie- 


\section{1}

FIGURA 6

Porcentaje que dice que gastamos demasiado en:
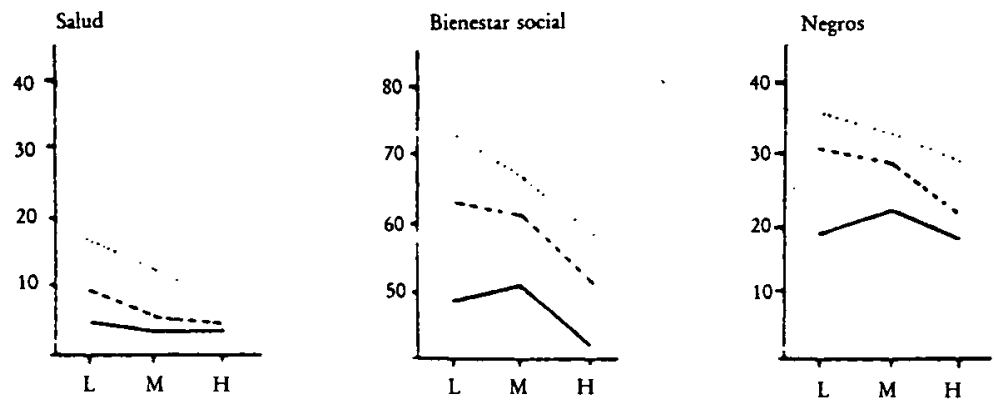

Porcentaje que dice que gastamos demasiado poco en:

Delincuencia

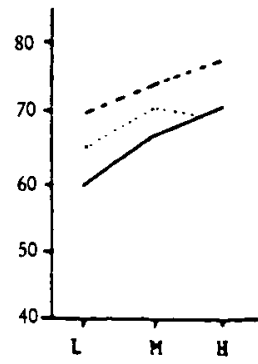

Lucha contra la droga

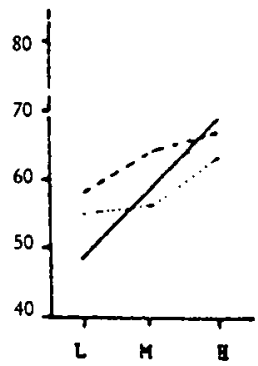

Armas, defensa

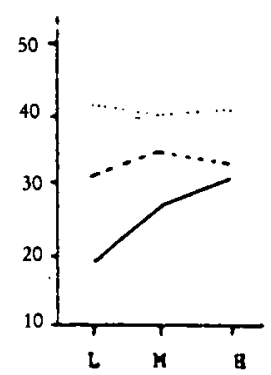

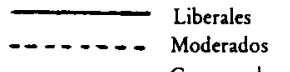

L: Consumidores ligeros

$\mathrm{M}$ : Consumidores medios

Conservadores

$\mathrm{H}$ : Consumidores duros

Exposición a la televisión y actitudes hacia el gasto público, de acuerdo con la autodesignación politica.

te problemas tradicionalmente "liberales»: salud, medio ambiente, ciudades, educación, ayuda exterior, bienestar y negros ${ }^{21}$. Los porcentajes de televidentes ligeros, medios y duros en las tres categorias políticas que dicen que EE.UU. gasta "demasiado» en salud, en bienestar y en los negros se muestra en la parte superior de la figura 6.

Aquí, en lugar de que los televidentes liberales duros adopten posiciones más cercanas a los conservadores, lo que ocurre es lo contrario: los televidentes conservadores duros, al igual que los moderados, convergen hacia una posición liberal en seis de los siete problemas. Cuanto mayor es la exposición, menos afirman que los EE.UU. gastan «demasiado". En estos seis problemas, la distancia media de 16 puntos de porcentaje entre televidentes liberales y conservadores ligeros es sólo de 9 puntos de porcentaje para los televidentes duros, siendo los conservadores los que explican la mayor parte de la convergencia $(t=8.2, p<.001)$. La excepción es el problema relativamente distante de la ayuda exterior.

Los cuatro problemas restantes son el delito, las drogas, la defensa y la exploración espacial. Los porcentajes de encuestados que dicen que EE.UU. 
está gastando «demasiado poco» en los tres primeros problemas pueden verse en la parte baja de la figura 6 . Aquí otra vez, con la excepción del espacio, los televidentes duros generalmente desean gastar más. Como estos son problemas algo más "conservadores», son los moderados y conservadores los que están en la "tendencia dominante de la televisión", adoptando una posición hacia un mayor gasto, y los televidentes liberales duros se sitúan cerca de ellos. En estos cuatro problemas, una dispersión media liberalconservadora de casi 10 puntos de porcentaje para los televidentes ligeros se compara con un salto de cuatro puntos de porcentaje entre los televidentes duros $(t=2.2, p<.12)$.

Para indagar más aún sobre la línea populista en la combinación política, por otra parte restrictiva, de la tipología del televidente duro, buscamos preguntas que combinarán perspectivas tanto sobre impuestos como sobre gastos. La ESG de 1980 nos permitió aislar a aquellos encuestados que se oponen a reducciones en los gastos del gobierno y, pese a ello, creen

\section{FIGURA 7}

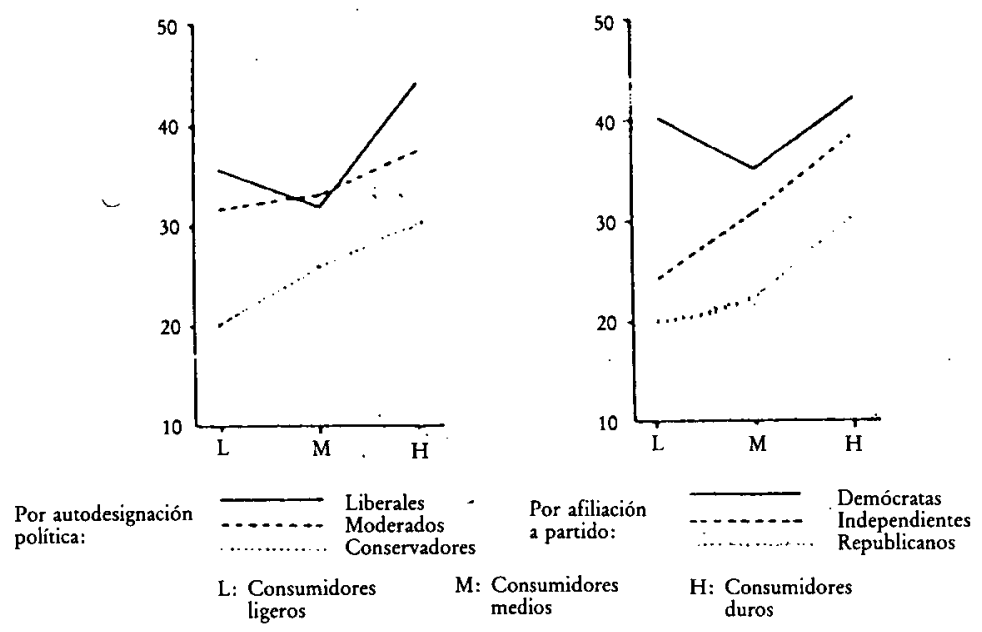

Relación entre ver televisión y oponerse a las reducciones del gasto público, pero afirmando que los impuestos son demasiado altos, de acuerdo con la autodesignación política y la afiliaciónn politica a un partido.

que sus impuestos son demasiado altos ${ }^{22}$. Como se muestra en la tabla 8 , los televidentes duros tienen mayor probabilidad de expresar esta posición contradictoria en cada subgrupo (a pesar de que la relación mantiene su significación de $\mathrm{p}<.05$ sólo en general y en seis de esos grupos. La figura 7 ilustra la alineación política.

Como en los otros problemas económicos, los liberales y moderados están juntos mientras que los televidentes conservadores duros se unen a la tendencia dominante liberal-moderada; la inclinación está en la dirección liberal (si entra en conflicto). Los televidentes Republicanos e Independientes duros también expresan actitudes más cercanas a las posiciones Democráticas que sus equivalentes políticos ligeros. Pero todos los televidentes 


\section{TABLA VIII}

Porcentaje de encuestados que se opone a los recortes en el gasto público y a la reducción de servicios, pero que piensa que sus impuestos son demasiado altos, por tiempo de exposición a la televisión $(N=1220)$

\begin{tabular}{lcccccc}
\hline & \multicolumn{4}{c}{ Exposición a la televisión } & \multirow{2}{*}{$\mathrm{CD}^{2}$} & Gamma \\
\cline { 2 - 6 } & $\begin{array}{c}\text { Ligera } \\
\%\end{array}$ & $\begin{array}{c}\text { Media } \\
\%\end{array}$ & $\begin{array}{c}\text { Dura } \\
\%\end{array}$ & & \\
\hline Total & 29 & 31 & 38 & +9 & $.13^{* \%}$
\end{tabular}

Control por:

Sexo

Hombres

Mujeres

$\begin{array}{lllrll}26 & 26 & 36 & +10 & .14^{*} & \\ 32 & 35 & 39 & +7 & .10 & (\mathrm{p}=.07)\end{array}$

Edad

Menos de 30

$30-54$

A partir de 55

$\begin{array}{lllrll}35 & 32 & 44 & +9 & .14 & \mathrm{p}=.07) \\ 27 & 35 & 41 & +14 & .19 * * & \\ 26 & 22 & 29 & +3 & .08 & \end{array}$

Educación

Sin educación superior

Con educación superior

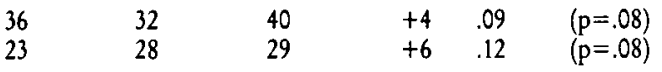

Ingresos

Bajos

Medios

Altos

$\begin{array}{lllrl}31 & 32 & 37 & +6 & .10 \\ 28 & 29 & 40 & +12 & .18^{*} \\ 28 & 30 & 35 & +7 & .10\end{array}$

Hábitat

Urbano

No urbano

$29 \quad 29 . \quad 40 \quad+11 \quad .16^{*}$

$\begin{array}{llllll}29 & 32 & 36 & +7 & .10 & (\mathrm{p}=.07)\end{array}$

Afiliación a partidos

Demócrata

Indpendiente

Republicano

\begin{tabular}{lllrll}
40 & 35 & 42 & +2 & \multicolumn{2}{l}{.04} \\
24 & 31 & 38 & +14 & $.19 \%$ & \\
20 & 22 & 30 & +10 & .17 & $(\mathrm{p}=.07)$
\end{tabular}

Autodesignación política

Liberal

Moderado

Conservador

$\begin{array}{lllrl}36 & 32 & 44 & +8 & .11 \\ 32 & 33 & 37 & +5 & .07 \\ 20 & 26 & 30 & +10 & .16 *\end{array}$

${ }^{*} p<.05$

$p<<.01$

${ }^{2} \mathrm{CD}=$ Diferencial de Cultivo, porcentaje de consumidores duros que da la respuesta menor porcentaje de consumidores ligeros que la emite.

tienen una probabilidad mayor de desear una combinación de más gasto social y de impuestos más bajos.

¿Es el "populimos comercial» el nuevo crisol americano?

La tendencia dominante cultural - y evidentemente política- de la televisión tiende a absorber las tendencias divergentes que tradicionalmente 
moldearon el proceso político y a contener sus propias contracorrientes. Los televidentes duros tienden más que los televidentes ligeros comparables a autodenominarse «moderados" pero adoptan posiciones que son inconfundiblemente conservadoras, excepto en problemas económicos.

Nuestro análisis muestra a pesar de que la exposición a la televisión hace disminuir las distancias entre conservadores, moderados y liberales, es la posición liberal la más débil entre los televidentes duros. La exposición a la televisión difumina las diferencias tradicionales, mezclándolas en una tendencia dominante más homogénea, e inclina la tendencia dominante hacia una posición de «línea dura» en los problemas relativos a las minorías y a los derechos personales. El populismo comercial a ultranza, con su mezcla de conservadurismo restrictivo y su liberalismo rastrero, es la contribución paradójica - y potencialmente volátil- de la televisión a las orientaciones políticas.

La «tendencia dominante de la televisión» podría ser el verdadero crisol del pueblo americano del siglo veinte. La mezcla creada es de significación central tanto para la teoría como para la práctica del autogobierno popular. Si nuestro trazado de la tendencia dominante es válido en general, los supuestos básicos sobre las orientaciones políticas, los medios de comunicación y el proceso democrático necesitan un análisis y una revisión con el fin de ajustarlos a la era de la televisión.

\section{Notas}

${ }^{1}$ El proyecto comenzó en 1967-1968 con un estudio para la Comisión Nacional sobre las causas y la prevención de la violencia. Continuó bajo el patrocinio del Comité Científico Asesor del Cirujano General de los Estados Unidos para la televisión y la conducta social, del Instituto Nacional de la Salud Mental, de la Oficina de la Casa Blanca para la política de telecomunicaciones, de la Asociación Médica Americana, de la Administración de los Estados Unidos para el envejecimiento y de la Fundación Nacional de la Ciencia.

George Gerbner, Larry Gross, Michael Morgan y Nancy Signorielli son miembros del equipo de investigación sobre los Indicadores Culturales en la Facultad de Comunicación de Annenberg, perteneciente a la Universidad de Pennsylvania.

${ }_{2}$ Es más probable que las nuevas tecnologías de las telecomunicaciones extiendan ese desafío en lugar de transformarlo. Perfilarán el objetivo y darán mayor capacidad de penetración al poder cultural de las telecomunicaciones en nuevas áreas en la actualidad en manos, casi exclusivamente ( $\mathrm{y}$ con frecuencia de manera menos eficiente o con mayor coste económico) de la imprenta. El ritual de ondas de las masas, al que ahora se denomina televisión, se ha convertido en algo esencial para el comercio, la aculturación y la gobernabilidad. Muy probablemente permanecerá básicamente intacta con el resurgimiento de la imprenta por medios electrónicos y se convertirá en el objeto de luchas cada vez más fuertes por el control.

${ }^{3}$ El trabajo de Chaffee, Graber, Mannheim, Patterson, Robinson y otros (véase p. ej., 11) ha establecido la relevancia de la televisión para las orientaciones políticas y proporciona un punto de partida útil para este estudio.

${ }^{4}$ Los informes iniciales se centraron en demostraciones llamativas del poder social y del riesgo personal (los «Perfiles de Violencia»). En los últimos años hemos usado nuestro banco acumulativo de datos de observaciones detalladas basadas en el análisis de más de 1.600 programas y 14.000 personajes, nuestras propias encuestas y también amplios archivos de datos de encuestas disponibles para el análisis secundario, para investigar presentaciones de televisión y concepciones relacionadas de los televidentes sobre mujeres y minorías, sobre el proceso de envejecimiento, sobre los científicos y miembros de otras profesiones, sobre la salud y la medicina, sobre las escenas sexuales, sobre las imágenes familiares y el impacto de la familia, sobre los logros y las aspiraciones educativas y sobre otros problemas. Hemos concebido ampliamente nuestra recogida de datos desde el principio, de modo que fuera posible el análisis de muchas tendencias y facetas del mundo de la televisión y de sus relaciones con las concepciones y actitudes de diversos grupos de televidentes. 
S Se ha encontrado que la sobreinclusión explica pautas diferenciales intragrupales por lo que se refiere al cultivo de imágenes de violencia, desconfianza, y alienación (6); concepciones de la ciencia y los científicos (8); creencias y prácticas relacionadas con la salud (7); estereotipos de rol sexual (14); y otros aspectos.

- El trabajo de Barnouw (1), Cantor (3), y Tuchman (15) describen en detalle el proceso de política institucional.

7 La muestra de 1975 fue extraída mediante una combinación de cuotas de bloque y muestreo probabilístico; los muestreos de los otros años fueron totalmente probabilísticos. Las muestras representan a personas a partir de los 18 años, angloparlantes y no institucionalizadas (véase el libro de códigos acumulativo del ESG de 1972 a 1980 para más detalles sobre muestreo y otros aspectos).

${ }^{8}$ La variable independiente en estos análisis es la cantidad de exposición a televisión medida en horas. La formulación concreta de la pregunta es: «En un día normal, ¿cuántas horas más o menos dedica usted personalmente, a ver la televisión?. Esta medida no se interpreta como un índice absolutamente exacto del tiempo medio de exposición. Más bien, la consideramos como un indicador de la exposición relativa y de la inmersión en el mundo de la televisión. Esta distribución varía en no más de 3,5 puntos por ciento dentro de cada uno de los cuatro años. Para los cuatro años combinados se obtiene una media de exposición de 2,92 horas (desviación típica $=2,17$ ) y la mediana es 2,48 . En treinta casos $(0,5 \%$ de la muestra total) no se obtuvo respuesta.

9 Estas pautas son generalmente independientes de los otros factores demográficos, aunque experimentan una ligera reducción bajo controles simultáneos. Esto también ocurre en el resultado de que son los encuestados más jóvenes y los más viejos los que ven más la televisión. La correlación simple entre la cantidad de exposición y una variable combinada de mediana edad es de $-0,14$. Al efectuar controles para las otras variables en la Tabla 1 , la correlación parcial es $-0,09$ (en ambos casos $\mathrm{p}<0,001$ ).

${ }_{10}$ Examinaremos especificamente diferencias intragrupales simples para evaluar la forma de las pautas de condicionamiento y mediación, e introduciremos términos de interacción multiplicativa en las ecuaciones de regresión jerárquica tras todos los controles de base y los efectos principales. Esto nos permite clarificar si las diferencias simples observadas entre los grupos son significativamente independientes de todos los demás factores.

"Es más probable que los televidentes duros digan que son demócratas dentro de cada uno de los 12 subgrupos que aparecen en la tabla 1 , y en todos los casos excepto uno (encuestados menores de 30 años) esta relación es significativa.

${ }_{12}$ Estos resultados se mantienen incluso cuando se controla la variación residual en el SES real dentro de cada uno de los grupos reales de SES.

${ }^{13}$ La tendencia política se midió con la pregunta, "oímos hablar mucho estos días sobre liberales y conservadores. Voy a mostrarle una escala de siete puntos en la que las opciones políticas que la gente puede mantener están ordenadas desde extremadamente liberal - punto $1-$ hasta extremadamente conservador - punto 7- ¿Dónde se situaría usted en esta escala?». La autodesignación en esta escala fue recodificada en tres categorías: los que contestaron "extremadamente liberal", "liberal" y «ligeramente liberal» (puntos 1, 2 y 3) fueron tratados como "liberales"; los puntos 5, 6 y 7 fueron clasificados como "conservadores" y los representantes del punto 4 «moderados», el centro de la escala. Los agrupamientos resultantes proporcionaron, para el conjunto de los cuatro años, 1.611 «liberales" $(22,2 \%), 2.254$ «moderados" $(39,4 \%)$, y 1.849 «conservadores" $(32,4 \%)$; 306 casos no contestaron $(5,1 \%)$.

${ }_{14}$ Por motivos de espacio los televidentes medios han sido omitidos de la tabla 3 . Todas las relaciones en las columnas de moderados y conservadores, sin embargo, son monotónicas a través del total de las tres categorías de exposición a la televisión; once de las dieciséis en la columna liberal son monotónicas. Además, los televidentes duros muestran una dispersión en torno a la media en la escala de siete puntos de autodesignación política significativamente menor que los televidentes ligeros, en general y dentro de la mayoría de los subgrupos. Para evitar los problemas de reducción de varianza en los subgrupos, los coeficientes de regresión sin estandarizar que reflejan la relación entre cantidad de exposición y el valor absoluto de las desviaciones de los encuestados con respecto al «centro" político de la muestra (controlando todo lo demás) fueron computados dentro de los principales subgrupos demográficos. Sin excepción, todos los coeficientes son negativos, lo que indica que los televidentes duros muestran consistentemente menos dispersión en torno a la media de la muestra. Esto es particularmente cierto para los encuestados con estudios universitarios, para los de renta media, para los más jóvenes y de mediana edad, para quienes no residen en ciudades, para las mujeres, y para aquellos cuya afiliación de partido es "Independiente" (todos los términos de interacción excepto región y sexo son significativos). Esto muestra que los televidentes duros tienden a elegir la autodesignación política "moderada" por encima de los efectos de estas potentes variables demográficas.

${ }^{15}$ La tendencia de los televidentes duros a designarse a sí mismos como «moderados" se mantiene dentro de cada uno de los cuatro años analizados, aunque hay variaciones en el tamaño de la asociación (es más débil en 1977 y más fuerte en 1978). Además, este efecto de moderación parece ser un correlato específico de la exposición a la televisión, y no un fenó- 
meno de exposición a los medios de comunicación en general: ni la exposición a la radio ni a la prensa escrita se asocia con resultados similares. El porcentaje de moderados entre oyentes de radio ligeros, medios y duros (definidos exactamente igual que los grupos de exposición a la televisión) es $38 \%, 39 \%$ y $39 \%$ respectivamente; del mismo modo, de los lectores diarios y ocasionales de prensa escrita, un $39 \%$ en ambos grupos se llaman a sí mismos moderados. Por tanto, es la exposición a la televisión, y no el uso de los medios de comunicación en general, lo que está asociado con la autodescripción de una disposición política de «moderadom. Por último, este hallazgo se replicó en un estudio nacional dirigido por Researcb and Forecasts, Inc. para la Connecticut Mutual Life Insurance Co. El porcentaje de moderados entre televidentes ligeros, medios y duros en este estudio es 41,48 y 49 respectivamente. Controlando la afiliación de partido, los datos son prácticamente idénticos a los de la ESG.

${ }^{16}$ Además de esas ocho preguntas, la ESG de 1977 contenía veinte ítems (la mayoría no repetidos) sobre actitudes hacia los negros, que se combinaron en seis índices, cada uno de ellos con una aceptable homogeneidad interna (con alphas de Cronbach de .50 a .60 ; el conjunto de todas las medidas arroja un alpha de .82). Cuatro de esos índices miden el apoyo a la segregación racial, bajo la forma de matrimonio interracial, apertura de alojamientos, integración escolar y evitación de negros. Una quinta escala se centra en las tendencias de los encuestados a mantener a los negros "en su sitio", y una sexta medida en el acuerdo de los encuestados con las explicaciones estereotípicas de las desventajas sociales de los negros. Al igual que sucedía con los ocho ítems repetidos, estos índices muestran que, para los liberales, una mayor exposición a la televisión significa un apoyo mayor a la segregación y unas manifestaciones más fuertes de racismo hacia los negros. Cinco de las seis relaciones son significativas entre los liberales. Sin embargo, ninguna de las comparaciones intragrupales son significativas para moderados o conservadores; cinco de los seis términos de interacción son negativos, dos de ellos significativamente. Una vez más, la exposición dura a la televisión cultiva la antiintegración y opiniones relacionadas sólo entre los liberales - aquéllos que son, por otra parte, menos opuestos a la igualdad racial-. De nuevo encontramos que no hay mucha diferencia entre moderados y conservadores.

${ }_{17}$ Con respecto a la homosexualidad, los encuestados indicaban si encontraban que «las relaciones sexuales entre dos adultos del mismo sexo" son "siempre malas", "casi siempre malas», "malas sólo algunas veces», "no son malas en absoluto»; nos centramos en aquéllos que responden "siempre malas». La pregunta fue formulada en 1977 y 1980 . Se incluyeron ítems que medían la aprobación de la legalización del aborto bajo seis condiciones específicas en cada uno de los cuatro años de la ESG que contenían preguntas sobre la cantidad de exposición a la televisión; estos ítems producen una escala de Guttman fiable (escalabilidad $=.80$, reproductibilidad $=.94$ ). Los encuestados fueron considerados "contrarios al aborto" si aprobaban la legalización del aborto en menos de tres situaciones o sólo en las tres situaciones más fáciles. Finalmente, una pregunta sobre si la marihuana debe ser legalizada se incluyó en 1975,1978 y 1980.

${ }^{18}$ Las mismas pautas se mantienen para actitudes hacia las relaciones sexuales prematrimoniales y extramatrimoniales. Los televidentes liberales ligeros tienen una probabilidad mucho menor de decir que esos comportamientos son «siempre malos», mientras que las respuestas de los televidentes liberales duros se aproximan a las de los moderados y conservadores. Al igual que sucedía con la integración racial a través del transporte escolar, moderados y conservadores muestran asociaciones significativas negativas entre cantidad de exposición a la televisión y desaprobación de las relaciones sexuales prematrimoniales -otro ejemplo de convergencia en ambas direcciones (la beta de la interacción, con todas las otras variables y los principales efectos en la ecuación es $-.18, \mathrm{p}<.01$ ).

19 Una sola pregunta (formulada en 1977 y en 1980) se refiere a los sentimientos de los encuestados sobre el comunismo, en un continuum de cuatro puntos desde «es la peor clase (de gobierno) de todas", hasta «es una buena clase de gobierno». Quince preguntas (todas ellas formuladas en 1977 y 1980) se refieren a si a cada uno de cinco tipos de personas se les debería dejar: a) pronunciar un discurso ante la comunidad de los encuestados, b) tener un libro en la biblioteca de la comunidad y c) enseñar en la universidad local. Subdividimos los cinco tipos en «izquierdistas» (ateos, comunistas, homosexuales, etc.) y "derechistas» (racistas, militaristas), y construimos dos índices del deseo de los encuestados de reducir la libertad de expresión de estos grupos. Los ítems anti-izquierdistas producían un alpha de $.90 \mathrm{y}$ el alpha de los anti-derechistas es .82 .

20 También se mantienen las mismas pautas básicas por lo que se refiere a las actitudes hacia la Enmienda de la Igualdad de Derechos (que se plantearon 50 en 1977), pero no de manera significativa. Entre los liberales, se opone a su aprobación el $17 \%$ de los televidentes ligeros, mientras que entre los televidentes duros lo hace un $20 \%$ Para los moderados y conservadores, que presentan una probabilidad mayor de oponerse a la enmienda, la exposición dura a la televisión significa mayor apoyo. Entre los moderados, el $28 \%$ de los televidentes ligeros y el $24 \%$ de los duros se oponen; entre los conservadores, al $40 \%$ de los televidentes ligeros y al $32 \%$ de los duros se oponían a que se aprobara. Una dispersión de 23 puntos de porcentaje entre los televidentes liberales y conservadores ligeros se reduce a la mitad (12 puntos) entre los televidentes duros. 
21 Estos siete ítems obtuvieron un alfa de .65. Los otros cuatro (exploración del espacio, control de la tasa de delincuencia, abuso de drogas y defensa/militarismo) comparten poca varianza común (alfa $=.28$ ) y representan claramente una dimensión diferente.

${ }_{22}$ En la ESG de 1980, se preguntó a los encuestados cuál sería su posición sobre una escala de siete puntos, con un punto 1 igual a kel gobierno deberia proporcionar menos servicios; reducir mucho los gastos" y el punto 7 kel gobierno debería continuar proporcionando servicios; no reducir gastos». Combinamos los encuestados que caían en los tres puntos más altos con aquellos que decían que la cantidad de impuestos que pagaban era demasiado alta, para construir una tipología de actitudes sobre gastos e impuestos. Nos centramos en el tercio $(32,1 \%)$ que adopta la posición contradictoria de oponerse a reducciones en los gastos al mismo tiempo que afirman que sus impuestos son muy elevados. El $40 \%$ quiere menos gastos e impuestos más bajos, el $13,9 \%$ desea reducir gastos pero no cree que sus impuestos sean demasiado altos y el $13,9 \%$ desea un gasto continuado y no cree que sus impuestos sean demasiado altos.

\section{Referencias}

1. BARNOW, E. (1975). Tube of Plenty: The Evolution of American Television. Nueva York. Oxford University Press.

2. Barwise, T. P., EhrenberG, A. S. C. y GoOdHARDT, G. J. (1982). Report on U.S. television viewing behavior. London Business School.

3. Cantor y Muriel, G. (1980). Prime-Time Television: Content and Control. Beverly Hills, Cal. Sage.

4. DeFleur, Melvin, L. y DeFleur, L. B. (1967). The Relative Contribution of Television as a Learning Source for Children's Occupational Knowledge. American Sociological Review, 32, 777-789.

5. Entman, Robert, M. y Paletz, D. L. (1980). Media and the Conservative Myth. Journal of Communication, 30 (4), Autumn 1980, 154-165.

6. Gerbner, G., Gross, L., Morgan, M. y Signorielli, N. (1980). The "Mainstreaming" of America: Violence Profile number 11. Journal of Communication, 30 (3), summer $1980,10-29$.

7. Gerbner, G., Gross, L., Morgan, M. y Signorielli, N. (1981). Health and Medicine on Television. New England Journal of Medicine, 305 (15), october 1981, 901-904.

8. Gerbner, G., Gross, L., Morgan, M. y Signorielli, N. (1981). Scientistics on the TV Screen. Society, 18 (4), may/june 1981, 41-44.

9. Gerbner, G., Gross, L., Signorielli, N. y Morgan, M. (1980). Aging with Television: Images on Television Drama and Conceptions of Social Reality. Journal of Comunication, 30 (1), winter 1980, 37-47.

10. Gerbner, G. y Signoreli, N. (1979). Women and Minorities in Television Drama, 1969-1978. The Annenbrg School of Communications. University of Pennsylvania.

11. Graber, D. A. (1980). Mass Media and American Politics. Washington D. C., Congressional Quarterly Press.

12. MORGAN, M. (1980). Longitudinal Patterns of Television Vieving and Adolescent Role Socialization. Unpublished Ph. D. dissertation. University of Pennsylvania.

13. Morgan, M. (1982). Symbolic Victimization and Real-World Fear. Paper presented at the Symposium on Cultural Indicators for the Comparative Study of Culture, Vienna, Austria, february 1982.

14. SignORIELLI, N. (1979). Television's Contribution to Sex Role Socialization. Paper presented at the Seventh Annual Telecomunications Policy Research Conference, Skytop, Pennsylvania, april 1979.

15. Tuchman, G. (1974). The TV Establishment: Programming for Power and Profit. Englewood Cliff, N.J., Prentice-Hall, 1974.

16. Volgy, T. J. y SChWARZ, J. E. (1980). TV Entertainment Programming and Sociopolitical Attitudes. Journalism Quarterly, 57 (1), 150-155.

17. Weigel, RuSSEl, H., LOOMIS, J. W. y SOJA, M. .J. (1980). Race Relations on Prime Time Television. Journal of Personality and Social Psychology, 39 (5), 884-893. 